\title{
Living Donor Liver Transplantation for Hepatocellular Carcinoma: Defining Criteria to Extend Indications
}

\author{
Irinel Popescu
}

Published online: 16 July 2008

(C) The Author(s) 2008

Hepatocellular carcinoma (HCC) is a widespread disease that develops mainly in cirrhotic liver and has a high mortality. Treatment is multimodal and includes resection, transplantation, transarterial chemoembolisation (TACE), percutaneous ablation procedures (PAP), and chemotherapy. Liver transplantation has gained a prominent role as a treatment, although there is no uniform agreement concerning which is the best approach [1].

Evidence-based medicine is lacking, as no large series or randomized studies are available. In resectable tumors, there is a debate between resection and liver transplantation as the treatment of choice [2]. Liver resection has lower perioperative risk, quicker recovery, and does not require immunosuppressant therapy. In cirrhotic patients, resections are usually limited and indicated only when the underlying cirrhosis is compensated. However, the recurrence rate is high. With recurrent tumors, liver transplantation has been proposed as the therapy of last resort (salvage transplantation) [3].

When the tumor is not resectable, either for local reasons (dimensions, number, and invasiveness) or the patient has advanced cirrhosis, liver transplantation appears to be the only potentially curative solution. The published data support the idea that the prognosis is good enough to allow inclusion of patients on the cadaveric waiting list if the patient fulfills the so-called "Milan criteria" (single tumor less than $5 \mathrm{~cm}$ in diameter or no more than three tumors, none larger than $3 \mathrm{~cm}$ ). United Network for Organ Sharing has incorporated the Milan criteria in a modified staging

\section{Popescu ( $\square)$}

Center of General Surgery and Liver Transplantation, Fundeni Clinical Institute, Sos. Fundeni 253, Sector 2,

72434 Bucharest, Romania

e-mail: irinel.popescu@icfundeni.ro system for HCC that is used to allocate organs. Patients with $\mathrm{HCC}$ receive 22 points, along with upgrades every 3 months [4].

Therefore, the majority of these patients will be listed for a cadaveric organ. The initial assumption that an available living donor will lead to a better outcome due to a shortened waiting time has not been conclusively proven; in fact, the recurrence rate was greater after a living donor transplantation than after a deceased donor transplantation in some studies [5]. While on the waiting list, patients can undergo an associated procedure (TACE, PAP) in order to keep them on the list and improve the oncological outcome. However, a significant number of patients will be removed from the list due to disease progression, despite the neoadjuvant treatment, because the waiting time is quite long in most programs. For these patients, living donor liver transplantation becomes the only opportunity. On the other hand, many patients with an $\mathrm{HCC}$ beyond the Milan criteria from the beginning only have transplantation as a potential cure. Due to this situation, an extension of the Milan criteria has been proposed [6]. Advocates of this extension consider the Milan criteria too restrictive, as patients with a significant chance of a cure could be excluded from transplantation. The most well-known extended criteria are the so-called San Francisco criteria: single nodules up to $6.5 \mathrm{~cm}$ or $2-3$ nodules up to $4.5 \mathrm{~cm}$, with the sum of diameters not exceeding $8 \mathrm{~cm}$. Other examples of extended criteria are those established by the Barcelona Clinic Liver Cancer which require a single nodule less than $7 \mathrm{~cm}, 2-3$ nodules less than $5 \mathrm{~cm}$, or $4-5$ nodules less than $3 \mathrm{~cm}$, and the 5-5 rule of $\mathrm{M}$. Makuuchi (Tokyo rule) which requires no more than five tumors, none of which may exceed $5 \mathrm{~cm}$ [7]. The criteria have been extended far enough that liver transplantation was proposed for all patients with no extrahepatic disease or invasion of the main trunk of the portal vein. 
An important issue to be addressed is the fact that the macromorphological characteristics of $\mathrm{HCC}$ give an imprecise estimate of the tumor's aggressiveness, for which more reliable criteria could be a poorly differentiated grade or microscopic vascular invasion. Recently, even more refined criteria, such as an allelic imbalance of microsatellites located adjacent to tumor-related genes, has been shown to be a predictor of HCC recurrence [8]. It is worth noting that all of these histological and molecular criteria require tumor biopsy.

It is clear that selection criteria are necessary, no matter how liberal the policy of a center towards liver transplantation for HCC. In the absence of such criteria, the results can be unsatisfactory, as questions arise concerning the benefit of the method as well as the financial coverage, particularly when treatment is assured by the state or insurance companies.

The Mount Sinai team has already reported an increased mortality after liver transplantation in patients with HCC for reasons that are unclear [6]. The risk for donors is not negligible, with mortality rates between $0.2 \%$ and $0.4 \%$ reported at the international level for all indications of living donor liver transplantation, and should be taken into consideration [4]. In patients with a high MELD (Model for End-Stage Liver Disease) score, the medical expenses can be intolerably high [9]. Therefore, selection criteria for the recipient remain important, even if a living donor is available.

In a retrospective study, Sotiropoulos et al. [10] identified three individual criteria that influence the results and, therefore, can be used as selection criteria. Age over 60 years, a MELD score above 22, and an alpha-fetoprotein greater than $400 \mathrm{ng} / \mathrm{ml}$ were associated with a poor prognosis.

Defining criteria that can predict the prognosis remains an important goal as long as many centers exceed the limits of transplantation for HCC, particularly with living donors. The criteria defined by Sotiropoulos and collegues [10] are useful, at least until more evidence-based medicine arising from large randomized studies becomes available.
Open Access This article is distributed under the terms of the Creative Commons Attribution Noncommercial License which permits any noncommercial use, distribution, and reproduction in any medium, provided the original author(s) and source are credited.

\section{References}

1. Van Kleek EJ, Schwartz JM, Rayhill SC, Rosen HR, Cotler SJ (2006) Liver transplantation for hepatocellular carcinoma: a survey of practices. J Clin Gastroenterol 40(7):643-647. doi: 10.1097/00004836-200608000-00018

2. De Carlis L, Sammartino C, Giacomoni A, Lautiero A, Slim AO, Pirotta V et al (2001) Surgical treatment of hepatocellular carcinoma: resection or transplantation? Results of a multivariate analysis. Chir Ital 53(5):579-586 Abstract

3. Hwang S, Lee SG, Moon DB, Ahn CS, Kim KH, Lee YJ et al (2007) Salvage living donor liver transplantation after prior liver resection for hepatocellular carcinoma. Liver Transpl 13(5):741746. doi:10.1002/lt.21157

4. Olsen SK, Brown RS Jr (2008) Live donor liver transplantation: current status. Curr Gastroenterol Rep 10(1):36-42. doi: 10.1007/s11894-008-0007-x

5. Lo CM, Fan ST, Liu CL, Chan SC, Ng IO, Wong J (2007) Living donor versus deceased donor liver transplantation for early irresectable hepatocellular carcinoma. Br J Surg 94(1):78-86. doi: $10.1002 / b j s .5528$

6. Gondolesi GE, Roayaie S, Munoz L, Kim-Schluger L, Schiano T, Fishbein TM et al (2004) Adult living donor liver transplantation for patients with hepatocellular carcinoma: extending UNOS priority criteria. Ann Surg 239(2):142-149. doi:10.1097/01.sla. 0000109022.32391.eb

7. Sugawara Y, Tamura S, Makuuchi M (2007) Living donor liver transplantation for hepatocellular carcinoma: Tokyo University series. Dig Dis 25(4):310-312. doi:10.1159/000106910

8. Schwartz ME, D'Amico F, Vitale A, Emre S, Cillo U (2008) Liver transplantation for hepatocellular carcinoma: are the Milan criteria still valid? Eur J Surg Oncol 34(3):256-262. doi: 10.1016/j.ejso.2007.07.208

9. Kogure T, Ueno Y, Kawagishi N, Kanno N, Yamagiwa Y, Fukushima K et al (2006) The model for end-stage liver disease score is useful for predicting economic outcomes in adult cases of living donor liver transplantation. J Gastroenterol 41(10):10051010. doi:10.1007/s00535-006-1887-x

10. Sotiropoulos GC, Lang H, Sgourakis G, Nadalin S, Molmenti EP, Radtke A et al (2008) Liberal policy in living donor liver transplantation for hepatocellular carcinoma: lessons learned. Dig Dis Sci. doi:10.1007/s10620-008-0319-6 